\title{
3 Research Square

\section{Low Birthweight and its Associated Factors During the Era of COVID 19 at Assosa General Hospital, Western Ethiopia, 2020}

Melkamu Senbeta Jimma ( $\sim$ melkasen12@gmaail.com )

Assosa University

Fisha Alebel GebreEyesus

Wolkite University

Ermias Chanie

Debre Tabor University

Demek Mesfin Belay

Debre Tabor University

Habtamu Bekele

Assosa University

Wubet Alebachew Bayih

Debre Tabor University

Demewoz Kefale Mekonen

Debre Tabor University

\section{Research Article}

Keywords: Assosa Hospital, Ethiopia, Low Birth weight, Newborn

Posted Date: July 13th, 2021

DOl: https://doi.org/10.21203/rs.3.rs-646765/v1

License: (c) (i) This work is licensed under a Creative Commons Attribution 4.0 International License.

Read Full License 


\section{Abstract}

Introduction: Low birth weight (LBW) is birth weight less than $2.5 \mathrm{~kg}$ regardless of gestational age. The prevalence of low birth weight in developing countries is $16.5 \%$. And it will help policy makers, health system planners, health care managers, and clinicians to perform evidence-based work and also help to contribute its own role to the achievement of World Health Organization goals by 2025. This study aims to assess low birth weight and its associated factors during the era of COVID 19 at Assosa General Hospital.

Method: A hospital-based cross-sectional study was conducted from December 01, 2020 to February 01, 2021 at Assosa General Hospital. A total of 335 samples were selected. Allocation was performed using the systematic random sampling technique. Data were collected using a structured questionnaire through interview and chart reviewing. It's checked for completeness and consistency. Then entered into Epi-Info and analyzed by using SPSS software version 22. First, descriptive analysis was carried out then, bivariate analysis was used to identify variables with $p$ value of less than 0.25 . Variables with $p$ value < 0.25 were entered into multivariate logistic regression analysis was used and confounding effect was controlled. Finally, those variables with $p$-value $<0.05$ were identified as significant determinants of LBW.

Result: The response rate of this research was $100 \%$. Based on this study, the prevalence of LBW was $11 \%$. Variables like no antenatal care [(AOR $=9 ; 95 \% \mathrm{Cl} 1.2-66)]$, fear of COVID19 is reason for Missed ANC follow up $[(A O R=9 ; 95 \% \mathrm{Cl} 1.2-66)]$ and type of pregnancy $[(A O R=6.35 ; 95 \% \mathrm{Cl} 1.7-23)]$ were identified as significant factors for this study.

Conclusion and Recommendations: The prevalence of LBW in the era of COVID 19 was $11 \%$. The associated factors of low birth weight are no antenatal care visit (ANC) during pregnancy and pregnancy type. So, concerned bodies were recommended to do more and more on ANC follow-up.

\section{Introduction}

Low birth weight (LBW) is a birth weight less than $2.5 \mathrm{~kg}$ regardless of gestational age (1). LBW infants are 20 times more at risk to develop complications and die as compared to normal-weight neonates (2). LBW is a key factor that affects about $15.5 \%$ of all newborns and that puts them at a higher risk of neonatal illness and death (3).

Globally, around $15-20 \%$ of birth are LBW; hence, it is considered as a great public health concern. Greater than twenty million infants, $(15 \%)$ percent of all births, were born with LBW. The incidence of LBW in developing countries (16.5\%) is more than double when compared with that in developed regions (7 percent). In sub-Saharan Africa, its accounts for $15 \%(4)$.

Hereafter, the World Health Organization noted a policy that targets to reduce LBW by $30 \%$ by the end of 2025. 
The magnitude of LBW in third-world countries is $16.5 \%$ or twice higher than that in first-world countries (7\%) (5).

In Ethiopia, still now LBW is considered as an agenda for the government, because it's a good indicator of the health of infant, and, also a major factor that determines the infant's physical, survival, and mental growth. It is also the main factor of infant and childhood illness, predominantly impairment of neurodevelopment problems such as mental retardation, inhibited growth and cognitive development, and chronic diseases later in life and learning challenges $(4,6)$.

It also leads to long-term handicap (7). It is associated with long-term morbidity during adulthood (8); weight at birth is a relevant indicator for the quality and development of fetus and a predictor of health throughout its life course (9).

The death of LBW babies is 40 times more than that for normal weight babies(10).

This is based on epidemiological observations that infants weighing less than $2,500 \mathrm{~g}$ are approximately 20 times more likely to die than heavier babies (7).

Therefore, the aim of this study is to assess the prevalence and associated factors of LBW at Assosa General Hospital.

This study will help policy makers, health system planners, health care managers, and clinicians to perform evidence-based work and it also helps to contribute its own role to the achievement of World Health Organization goals by 2025.

\section{Objectives}

\section{General Objective}

To assess to assess the prevalence and associated factors of LBW during the era of COVID 19 at Assosa General Hospital, Western, Ethiopia, 2020

\section{Specific Objective}

To assess the prevalence of low birth weight during the era of COVID 19 at Assosa General Hospital, Western Ethiopia, 2020

To determine factors associated with low birth weight during the era of COVID 19 at Assosa General Hospital, Western Ethiopia, 2020

\section{Methods And Materials}

\section{Study Area}


The study was conducted in Assosa General Hospital, which is the capital city of Benishangul Gumuze regional state. It is located $661 \mathrm{~km}$ far from Addis Ababa in the Western part of Ethiopia.

Based on the 2007 Census conducted by the Central Statistical Agency of Ethiopia, The BenishangulGumuz Region has a total population of 784,345 , of which, 398,655 were men and 385,690 were women. The hospital serves for many other hospitals and kebeles. Obstetrics and gynecology wards have separate labor, delivery, and postnatal care services and have family planning, high-risk maternity, antenatal care (ANC), and gynecological outpatient departments.

\section{Study Design and study period}

Hospital-based cross-sectional study was conducted among mothers who delivered in Assosa General Hospital from December 01, 2020 to February 01, 2021.

\section{Population}

\section{Source Population}

All mothers who gave birth at the Assosa General Hospital.

\section{Study Population}

All mothers who gave birth at the Assosa General Hospital in our study area and study period.

\section{Sample Size Determination}

The required sample size was determined using single population proportion formula by taking $14.9 \%$ from similar research performed at two hospitals in the delivery clinics of Northwest part of Ethiopia(11).

By using the $95 \% \mathrm{Cl}$ and $5 \%$ marginal error (d)

$$
\frac{\mathrm{N}=(\mathrm{Z} \alpha / 2)^{2} \cdot \mathrm{p}(1-\mathrm{p})}{\mathrm{d}^{2}}
$$

where $\mathrm{n}=$ number of sample size

$(\mathrm{Za} / 2)=$ the value of a under standard normal table for the given value of confidence level $=1.96$

$d^{2}=$ margin of error

$P=$ prevalence of low birth weight $=14.9 \%$

Therefore, $\mathrm{n}=\underline{(1.96)^{2} .0 .149(1-0.149)=304.4}$ 
by adding $10 \%$ of the nonresponse rate. The final total sample size was 335 .

\section{Sampling Techniques and its Procedure}

Systematic random sampling was used to select the study participants. According to previous delivery reports of the Assosa General Hospital, the delivery rate is 1010 per quarter of a year. Our data collection period was for 2 months. Therefore, during our data collection period, we expected around 674 women for delivery. Therefore, for data collected from 335 women, we have used a k value of 2 . The lottery method was used to get the initial study participants. Finally, study participants were enrolled to this study with every two intervals.

\section{Inclusion and Exclusion Criteria}

\section{Inclusion Criteria}

All mothers who gave live birth during the study period and after birth with no missing information were included in this study.

\section{Exclusion Criteria}

Neonates with congenital anomalies and still birth were excluded in this study.

\section{Data Collection process}

Newborns whose weight was measured within one hour of delivery were enrolled in this study. Data were collected from the selected mothers through interview and newborn chart review to find variables.

\section{Data quality control and data analysis}

Data were checked for completeness and consistency and entered to Epi info, and it was then exported to SPSS version 22 for analysis. First, data management was performed. A descriptive analysis was then performed to determine the prevalence of LBW. Bivariate analysis was used to check whether the independent variables was associated with the dependent variable. Those variables with $p$-value of $<0.25$ in bivariate logistic regression analysis were included in the multivariate logistic regression analysis for controlling the possible effect of confounders. Finally, variables with P-value $\leq 0.05$ were identified as significantly associated factors.

\section{Operational Definitions}

Birth weight - is the first weight of the newborn obtained after birth. For live births, birthweight should preferably be measured in the first hour of life.

World Health Organization defines low birth weight (LBW) as birth weight less than $2500 \mathrm{~g}$ irrespective of gestational age (1).

\section{Study Variables}




\section{Dependent Variable}

Low birth weight (LBW)

\section{Independent Variables}

- Socio demographic characteristics such as maternal age, maternal occupation, religion, ethnicity, marital status and residence, educational status of mother and father

- Maternal lifestyle (chat chewing, drinking alcohol, cigarette smoking)

- Maternal medical and obstetrics related characteristics such as PIH, maternal weight, gravidity, parity, birth interval, history of abortion, renal disease, GA at birth, ANC follow up, fear of COVID19 is reason for Missed ANC follow up, number of ANC follow-up.

- Nutritional factors MUAC, BMI, maternal height, maternal weight

- Neonatal factors such as gestational age, newborn sex, birth interval, and number of children.

\section{Results}

A total of 335 mothers were eligible to participate in the study, and we had a $100 \%$ respondent rate. The associated factors of LBW were no antenatal care visit (ANC) [(AOR $=9 ; 95 \% \mathrm{Cl} 1.2-66)]$ during pregnancy, fear of COVID19 is reason for Missed ANC follow up [(AOR $=9 ; 95 \% \mathrm{Cl} 1.2-66)]$ and type of pregnancy $[(\mathrm{AOR}=6.35 ; 95 \% \mathrm{Cl} 1.7-23)]$.

\section{Sociodemographic Characteristics of Mothers}

Among 335 mothers, the majority of them were in the age range of 20 to 24 and 25-29 years, respectively. Those mothers who are found to age greater than or equal to 35 account $26(7.8 \%)$.

One hundred seventy-nine of them were orthodox in their religion. The marital status of 320 (95.5\%) mothers was married. The occupational status of mothers as government employee, private employee, merchant, housewife, student, and others was 225 (67.2\%), 46(4.8\%), 34(10.1\%), 17(5.1\%), and 13(3.9\%) respectively.

Among all participants, around 239(71.3\%) resided in the urban area (Table 1). 
Table 1

Sociodemographic characteristics of the participants at Assosa General Hospital, Ethiopia, 2020

\begin{tabular}{|c|c|c|c|}
\hline Variables & Categories & Frequency & $\%$ \\
\hline \multirow[t]{5}{*}{ Age of Mother } & $<20$ & 61 & 18.2 \\
\hline & $20-24$ & 122 & 36.4 \\
\hline & $25-29$ & 107 & 31.9 \\
\hline & $30-34$ & 19 & 5.7 \\
\hline & $>/=35$ & 26 & 7.8 \\
\hline \multirow[t]{4}{*}{ Respondent Religion } & Orthodox & 179 & 48.1 \\
\hline & Muslim & 135 & 36.3 \\
\hline & Protestant & 54 & 14.5 \\
\hline & Other & 4 & 1.1 \\
\hline \multirow[t]{4}{*}{ Mother age } & $15-19$ & 10 & 2.7 \\
\hline & $20-24$ & 85 & 22.8 \\
\hline & $25-30$ & 126 & 33.9 \\
\hline & $>30$ & 151 & 40.6 \\
\hline \multirow[t]{5}{*}{ Mothers' education } & Cannot read and write & 6 & 1.8 \\
\hline & Read and write & 23 & 6.9 \\
\hline & Primary & 32 & 9.6 \\
\hline & Secondary and above & 53 & 15.8 \\
\hline & Diploma and above & 221 & 66 \\
\hline \multirow[t]{4}{*}{ Marital status } & Married & 320 & 95.5 \\
\hline & Single & 3 & 0.9 \\
\hline & Divorced & 6 & 1.8 \\
\hline & Widowed & 6 & 1.8 \\
\hline \multirow[t]{5}{*}{ Mother Occupation } & Government employer & 225 & 67.2 \\
\hline & Merchant & 46 & 4.8 \\
\hline & Housewife & 34 & 10.1 \\
\hline & Student & 17 & 5.1 \\
\hline & Other & 13 & 3.9 \\
\hline
\end{tabular}




\begin{tabular}{|llll|}
\hline Variables & Categories & Frequency & $\%$ \\
\hline Ethnicity & Amhara & 130 & 38.8 \\
& Oromo & 68 & 20.3 \\
& Shenasha & 56 & 16.7 \\
& Other & 81 & 24.2 \\
Residence & Rural & 96 & 28.7 \\
& Urban & 239 & 71.3 \\
Monthly income & $<1000$ & 45 & 13.4 \\
& $1001-3000$ & 56 & 16.7 \\
& $3001-5000$ & 56 & 16.7 \\
& $>5000$ & 178 & 53.1 \\
\hline
\end{tabular}

\section{Lifestyle-related factors}

Based on this study, only $5(1.5 \%)$ of mothers had a history of chat chewing during pregnancy and around $143(42.7 \%)$ had a history of alcohol use. Types of fuel used were wood, kerosine, and electricity accounts $271(80.9 \%), 8(2.4 \%)$, and $56(16.7 \%)$, respectively. Twelve (3.6\%) of mothers faced physical violence during pregnancy (Table 2). 
Table 2

Lifestyle- and health-related characteristics of mothers at Assosa General Hospital, Ethiopia, 2020

\begin{tabular}{|llll|}
\hline Variable & Category & Frequency & Percentage \\
\hline History of Chat chewing & Yes & 5 & 1.5 \\
\hline History of Smoking & No & 330 & 98.5 \\
\hline History of Alcohol Use & Yes & 0 & 0 \\
& No & 335 & 100 \\
\hline Separate room for kitchen & Yes & 143 & 42.7 \\
& No & 192 & 57.3 \\
\hline Type of full used & Yes & 291 & 86.9 \\
& No & 44 & 13.1 \\
\hline Physical Violence during Pregnancy & Yes & 12 & 80.9 \\
& Wood & 271 & 2.4 \\
& Kerosine & 8 & 16.7 \\
\hline
\end{tabular}

\section{Obstetrics and medical related factors}

The descriptive statistics of obstetrics-related factors are evidenced by different variables. Based on this finding, $141(42.1 \%)$ of mothers were Multipara, $13(3.9 \%)$ of the mother's pregnancy type were Multiple (twin). Mothers who had an ante nata care visits (ANC) were 316(94.3\%) and mothers who did not had an ante nata care visits were 19(5.7\%). Mothers who missed ANC due to fear of COVID 19 were 19(5.7\%) whereas mothers who didn't fear COVID 19 during ANC visit were 316(94.3\%) (Table 3). 
Table 3

Obstetric- and medical-related characteristics of mothers at Assosa General Hospital, Ethiopia, 2020

\begin{tabular}{|c|c|c|c|}
\hline Variable & Category & Frequency & Percentage \\
\hline \multirow[t]{2}{*}{ Parity } & Multipara & 141 & 42.1 \\
\hline & Primipara & 194 & 57.9 \\
\hline \multirow[t]{2}{*}{ Gravidity } & Multigravida & 145 & 43.3 \\
\hline & Primigravida & 190 & 56.7 \\
\hline \multirow[t]{2}{*}{ Pregnancy Type } & Singleton & 322 & 96.1 \\
\hline & Multiple & 13 & 3.9 \\
\hline \multirow[t]{2}{*}{ Pregnancy } & Intended & 310 & 92.5 \\
\hline & Unintended & 25 & 7.5 \\
\hline \multirow[t]{2}{*}{ ANC Visit } & Yes & 316 & 94.3 \\
\hline & No & 19 & 5.7 \\
\hline \multirow[t]{2}{*}{ Fear of COVID19 is reason for Missed ANC follow up } & Yes & 19 & 5.7 \\
\hline & No & 316 & 94.3 \\
\hline \multirow[t]{4}{*}{ Number of ANC Visit } & One & 26 & 7.8 \\
\hline & Two & 113 & 33.7 \\
\hline & Three & 89 & 26.6 \\
\hline & Four & 88 & 26.3 \\
\hline \multirow[t]{4}{*}{ Where did you visit ANC } & Hospital & 172 & 51.3 \\
\hline & Private Clinic & 37 & 11 \\
\hline & Health Center & 102 & 30.4 \\
\hline & Health post & 5 & 1.5 \\
\hline \multirow[t]{2}{*}{ Folic Acid Use } & Yes & 312 & 93.1 \\
\hline & No & 23 & 6.9 \\
\hline \multirow[t]{2}{*}{ Family Planning Use } & Yes & 303 & 90.4 \\
\hline & No & 32 & 9.6 \\
\hline \multirow[t]{2}{*}{ History of Abortion } & Yes & 27 & 8.1 \\
\hline & No & 308 & 91.9 \\
\hline
\end{tabular}




\begin{tabular}{|llll|}
\hline Variable & Category & Frequency & Percentage \\
\hline History of APH & Yes & 10 & 3 \\
\hline History of PIH & No & 325 & 97 \\
\hline History of Anemia & Yes & 18 & 5.4 \\
& No & 317 & 94.6 \\
\hline History of malaria during Pregnancy & Yes & 39 & 11.6 \\
& No & 296 & 88.4 \\
\hline HIV Status & Yes & 40 & 11.9 \\
& No & 295 & 88.1 \\
\hline
\end{tabular}

\section{Nutrition-related factors}

Regarding nutritional factors, mothers who took additional diet during pregnancy were 317(94.6\%) but who did not take additional diet were 18(5.4). During their pregnancy time MUAC measurement result of mothers was greater than or $>/=22$ centimeter. A total of $303(99.4 \%)$ of them were weighing greater than or equal to $50 \mathrm{~kg}$ (Table 4).

Table 4

Nutrition-related characteristics of mothers at Assosa General Hospital, Ethiopia, 2020

\begin{tabular}{|llll|}
\hline Variable & Category & Frequency & Percentage \\
\hline Additional diet intake & Yes & 317 & 94.6 \\
& No & 18 & 5.4 \\
Maternal MUAC & $<22 \mathrm{~cm}$ & 16 & 4.8 \\
& $>/=22 \mathrm{~cm}$ & 319 & 95.2 \\
Maternal Hight & $<150 \mathrm{~cm}$ & 16 & 4.8 \\
& $>/=150 \mathrm{~cm}$ & 319 & 95.2 \\
Maternal Weight & $<50 \mathrm{KG}$ & 2 & 0.6 \\
& $>/=50 \mathrm{KG}$ & 333 & 99.4 \\
\hline
\end{tabular}




\section{Newborn related factors}

Those newborns with gestational age of $<37$ weeks and $>/=37$ weeks accounted for $34(10.1 \%)$ and $303(89.9 \%)$, respectively. The proportion of both sexes of newborns was approximately $50 \%$. Forty six percent of these newborns were born with a birth interval of two to three years. From all study participants, households who had three to five children were 122(36.4\%) (Table 5).

Table 5

Newborn-related characteristics at Assosa General Hospital, Ethiopia, 2020

\begin{tabular}{|llll|}
\hline Variable & Category & Frequency & Percentage \\
\hline Gestational Age & $<37$ week & 34 & 10.1 \\
& $>/=37$ week & 303 & 89.9 \\
\hline Sex & Male & 161 & 48.1 \\
& Female & 174 & 51.9 \\
Birth Weight & $<2.5 \mathrm{~kg}$ & 36 & 10.7 \\
& $>/=2.5 \mathrm{~kg}$ & 299 & 89.3 \\
Birth Interval & $<2$ & 132 & 39.4 \\
& $2-3$ & 154 & 46 \\
& $>3$ & 49 & 14.6 \\
Number of Children & $</=2$ & 97 & 29 \\
& $3-5$ & 122 & 36.4 \\
& $>/=5$ & 116 & 34.6 \\
\hline
\end{tabular}

\section{Prevalence of LBW}

Among 335 study participants, the prevalence of LBW is 11\% (Figure-1).

\section{Factors Associated with LBW}

Based on the study conducted, child age, no ANC follow-up, COVID19 is reason for Missed ANC and type of pregnancy were identified as significant factors for full vaccination (Table 6). 
Table 6

Bivariable and multivariable logistic regression analysis with $p$ value less than 0.25

\begin{tabular}{|c|c|c|c|c|c|c|}
\hline \multirow[t]{2}{*}{ Variables } & \multirow[t]{2}{*}{ Category } & \multicolumn{2}{|c|}{ Low birth weight } & \multirow{2}{*}{$\begin{array}{l}\text { Crude OR } \\
(95 \% \mathrm{Cl})\end{array}$} & \multirow{2}{*}{$\begin{array}{l}\text { Adjusted OR } \\
(95 \% \mathrm{Cl})\end{array}$} & \multirow{2}{*}{$\begin{array}{l}\mathrm{P} \\
\text { Value }\end{array}$} \\
\hline & & Yes & No & & & \\
\hline \multirow[t]{2}{*}{ ANC follow-up } & Yes & $29(9.2)$ & $287(90.8)$ & 1 & 1 & 1 \\
\hline & No & $7(36.8)$ & 12(70.6) & $5.7(2,15.8)$ & $9(1.2,66)$ & 0.03 \\
\hline \multirow{2}{*}{$\begin{array}{l}\text { Fear of COVID19 } \\
\text { is reason for } \\
\text { Missed ANC } \\
\text { follow up }\end{array}$} & Yes & $7(36.8)$ & \multirow{2}{*}{$\begin{array}{l}12(70.6) \\
287(90.8)\end{array}$} & $5.7(2,15.8)$ & $9(1.2,66)$ & 0.03 \\
\hline & No & $29(9.2)$ & & 1 & 1 & 1 \\
\hline \multirow{2}{*}{$\begin{array}{l}\text { Family Planning } \\
\text { use }\end{array}$} & Yes & $29(9.6)$ & $274(90.4)$ & 1 & 1 & 1 \\
\hline & No & $7(21.9)$ & $25(78.1)$ & $0.4(0.15,0.95)$ & $1,4(0.4,4.9)$ & 0.57 \\
\hline \multirow[t]{2}{*}{ Folic Acid Use } & Yes & $31(9.9)$ & $281(90.1)$ & 1 & 1 & 1 \\
\hline & No & $5(21.7)$ & 18(78.3) & $2.5(0.9,7)$ & $0.55(0.1,3.8)$ & 0.55 \\
\hline \multirow[t]{2}{*}{$\mathrm{Hx}$ of Anemia } & Yes & 12(29.3) & $29(70.3)$ & 1 & 1 & 1 \\
\hline & No & $24(8.2)$ & $270(91.8)$ & $0.2(0.09,0.47)$ & $0.37(0.12,1.2)$ & 0.084 \\
\hline \multirow[t]{2}{*}{ Hx of Malaria } & Yes & $12(28.6)$ & $30(71.4)$ & 1 & 1 & 1 \\
\hline & No & $24(8.2)$ & 269(91.8) & $0.23(0.1,0.45)$ & $0.33(0.1,1)$ & 0.56 \\
\hline \multirow[t]{2}{*}{ Gestational Age } & $<37$ & $8(23.5)$ & $26(26.5)$ & $0.33(0.13,0.81)$ & 1 & 0.13 \\
\hline & $>37$ & $28(9.3)$ & $273(90.7)$ & 1 & $0.06(0.34,1)$ & \\
\hline \multirow[t]{2}{*}{ Pregnancy Type } & Singleton & $31(9.1)$ & 291(63.2) & 1 & 1 & 1 \\
\hline & Multiple & $5(38.5)$ & $8(61.5)$ & $5.87(1.8,19)$ & $6.35(1.7,23)$ & 0.006 \\
\hline
\end{tabular}

\section{Discussion}

The prevalence of LBW at Assosa General hospital was 11\%. Most of the studies conducted in Ethiopia agree with this study. In contrary to that, there are studies which showed high prevalence of LBW. Studies from different areas revealed that the prevalence of LBW at Adwa General Hospital, Northern Ethiopia was $10 \%(5), 9.4 \%$ at Southeast of Iran(12), 14.9\% in Northwest part of Ethiopia(13), 15.8\% at Wolaita Sodo University Teaching and Referral Hospital, Southern Ethiopia(14), 18\% at Kambata-Tembaro zone, southern Ethiopia(15), 20.73\% in Central region of India(16), 21\% at Dire Dawa City, Eastern Ethiopia(17), and $24 \%$ at public hospital in North Wollo Zone, Amhara region Ethiopia(25). The variation in prevalence rate of low birth weight might be due to the variation in study area, study time, study sample size, infrastructure for health care, awareness, accessibility of health institution, and so on. 
Based on our study, the identified associated factors of LBW were absence of antenatal care visit (ANC) and type of pregnancy.

Regarding antenatal care visit (ANC), mothers with no antenatal care visit (ACV) were 9 times more likely to have LBW infants than those who had antenatal care visits (ANC) (AOR $=9 ; 95 \% \mathrm{Cl} 1.2-66)$. This study is in line with a study conducted in Dessie, Amhara, Ethiopia (18), West Bengal, India (19), Ataye Primary Hospital, North Shoa, Ethiopia(20), Kambata-Tembaro zone, southern Ethiopia(15), Debreberhan Referral Hospital(21) Amhara Regional State Referral Hospitals of Ethiopia(22), Jimma Medical Center (JMC)(23), Northwest part of Ethiopia (22) and Northwest part of Ethiopia (13) In fact, this might be because in those mothers who had no ANC follow-up, there were difficulties in knowing health problems timely, like danger sign of pregnancy, and social misconducts that can affect the birth outcome of the neonate and if they did not have ANC visit at all, they may not receive iron supplementation and advise about lifestyle and nutrition.(24).

The other factor associated with low birth weight was fear of COVID19 is reason for Missed ANC follow up. Mothers who were missed ANC visit due to fear of COVID 19 were 9 times high likely to get LBW infants than those mothers who didn't have fear (AOR $=9 ; 95 \% \mathrm{Cl} 1.2-66)$. The reason for this might be, due to inaccessibility of personal protective equipment, lack of awareness or misunderstanding, increment of COVID 19 mortality and morbidity, poor screening and management of COVID and negligence of covid 19 prevention strategy.

The final factor associated with LBW is the type of pregnancy. Mothers who had a twin pregnancy were six times more likely to have LBW infants than who had a singleton pregnancy (AOR $=6.35 ; 95 \% \mathrm{Cl} 1.7-$ 23). This might be due to nutritional sharing of fetus from mother during pregnancy.

\section{Conclusions And Recommendations}

The prevalence of LBW in the era of COVID 19 was $11 \%$. The associated factors of low birth weight are no antenatal care visit (ANC) during pregnancy, fear of COVID19 is a reason for Missed ANC follow up and pregnancy type. So, concerned bodies were recommended to do more on ANC follow-up and misunderstanding of mothers COVID 19 and ANC.

\section{Abbreviations}

ANC Antenatal Care

APH Ante Partum Hemorrhage

AOR Adjusted Odds Ratio

BMI Body Mass Index

Cl Confident Interval 
COR Crude Odds Ratio

EDHS Ethiopia Demographic and Health Survey

FMOH Federal Ministry of Health

HIV Human Immune Deficiency Virus

IUGR Intra Uterine Growth Restriction

LBW Low Birth Weight

MUAC Mid Upper Arm Circumference

PIH Pregnancy Induced Hypertension

SGA Small for Gestational Age

SPSS Statistical Package Social Science

UNICEF United Nations Children's Fund

WHO World Health Organization

\section{Declarations}

\section{Ethics approval and consent to participate}

Ethical approval was obtained from the ethical review committee of Assosa University, College of Health Sciences on behalf of the nursing department. It was conducted in accordance with the Declaration of Helsinki. Also, participants under 18 years of age were approved by the ethics committee to provide informed consent on their own behalf. A permission letter was written for Regional health bureau. Then, Regional health bureau wrote to Assosa General Hospital manager. Finally, Assosa General Hospital manager wrote a letter for maternity and neonatal unit. Then written informed consent was obtained from each study participant.

Consent for publication: Not applicable

Availability of data and material: All required data are available

\section{Competing interests}

The authors declare that there are no conflicts of interest regarding the publication of this paper.

Funding

No funding available 


\section{Authors' Contributions}

MS, FA, ES, DM, HB, WA, DK: All authors made a significant contribution to the work reported, whether that is in the conception, study design, execution, acquisition of data, analysis and interpretation, or in all these areas; took part in drafting, revising or critically reviewing the article; gave final approval of the version to be published; have agreed on the journal to which the article has been submitted; and agree to be accountable for all aspects of the work.

\section{Acknowledgments}

First, we would like to thank to our data collectors, participants, and administratives of Assosa General Hospital. We would also like to thank College of Health Science Departement of Nursing.

\section{References}

1. Organization WH. International Statistical Classification of Diseases and Related Health Problems10. Disorders related to short gestation and low birth weight, not elsewhere classified: . 2016.

2. UNICEF W. Low Birth Weight: Country, regional and global estimates. 2004.

3. Wilding S, Ziauddeen N, Roderick P, Smith D, Chase D, Macklon N, et al. Are socioeconomic inequalities in the incidence of small-for-gestational-age birth narrowing? Findings from a population-based cohort in the South of England. BMJ open. 2019;9(7):e026998.

4. (Barker DJPe. Fetal and infant origins of disease. BMJ Books, London,. 1992.

5. Gebregzabiherher $Y$, Haftu A, Weldemariam S, Gebrehiwet $H$. The prevalence and risk factors for low birth weight among term newborns in Adwa General Hospital, Northern Ethiopia. Obstetrics and gynecology international. 2017;2017.

6. Chiarotti F, Castignani A, Puopolo M, Menniti-Ippolito F, Minniti De Simeonibus E, Di Paolo A. Effects of socio-environmental factors on neurocognitive performance in premature or low-birth weight preschoolers. Annali dell'Istituto superiore di sanità. 2001;37(4):553-9.

7. Goldenberg RL, Culhane JF. Low birth weight in the United States. The American journal of clinical nutrition. 2007;85(2):584S-90S.

8. Sidebotham P, Fraser J, Covington T, Freemantle J, Petrou S, Pulikottil-Jacob R, et al. Understanding why children die in high-income countries. The Lancet. 2014;384(9946):915-27.

9. Varea C, Terán JM, Bernis C, Bogin B, González-González A. Is the economic crisis affecting birth outcome in Spain? Evaluation of temporal trend in underweight at birth (2003-2012). Annals of human biology. 2016;43(2):169-82.

10. Martin RJ, Fanaroff AA, Walsh MC. Neonatal-perinatal medicine: diseases of the fetus and infant: Mosby; 2002. 
11. Tesfaye TD, Temesgen WA, Kasa AS. Vaccination coverage and associated factors among children aged 12-23 months in Northwest Ethiopia. Human vaccines \& immunotherapeutics. 2018;14(10):2348-54.

12. Momeni M, Danaei M, Kermani AJN, Bakhshandeh M, Foroodnia S, Mahmoudabadi Z, et al. Prevalence and risk factors of low birth weight in the Southeast of Iran. International journal of preventive medicine. 2017;8.

13. Kumlachew W, Tezera N, Endalamaw A. Below normal birth weight in the Northwest part of Ethiopia. BMC research notes. 2018;11(1):1-7.

14. Lake EA, Olana Fite R. Low birth weight and its associated factors among newborns delivered at wolaita sodo university teaching and referral hospital, southern Ethiopia, 2018. International journal of pediatrics. 2019;2019.

15. Alemu A, Abageda M, Assefa B, Melaku G. Low birth weight: prevalence and associated factors among newborns at hospitals in Kambata-Tembaro zone, southern Ethiopia 2018. The Pan African Medical Journal. 2019;34.

16. Mallick A. Prevalence of low birth weight in India and its determinants: Insights from the National Family Health Survey (NFHS), 2015-2016. Anthropologischer Anzeiger; Bericht Uber die Biologischanthropologische Literatur. 2021.

17. Sema A, Tesfaye F, Belay Y, Amsalu B, Bekele D, Desalew A. Associated Factors with Low Birth Weight in Dire Dawa City, Eastern Ethiopia: A Cross-Sectional Study. BioMed research international. 2019;2019.

18. Jember DA, Menji ZA, Yitayew YA. Low Birth Weight and Associated Factors Among Newborn Babies in Health Institutions in Dessie, Amhara, Ethiopia. Journal of multidisciplinary healthcare. 2020;13:1839.

19. Pal A, Manna S, Das B, Dhara PC. The risk of low birth weight and associated factors in West Bengal, India: a community based cross-sectional study. Egyptian Pediatric Association Gazette. 2020;68(1):1-11.

20. Dilnessa T, Belete E, Tefera M. Prevalence of Low Birth Weight and Associated Factors among New Born Babies in Ataye Primary Hospital, North Shoa, Ethiopia, 2018.

21. Hailu LD, Kebede DL. Determinants of low birth weight among deliveries at a referral Hospital in Northern Ethiopia. BioMed research international. 2018;2018.

22. Asmare G, Berhan N, Berhanu M, Alebel A. Determinants of low birth weight among neonates born in Amhara Regional State Referral Hospitals of Ethiopia: unmatched case control study. BMC research notes. 2018;11(1):1-7.

23. Seid S, Tolosa T, Adugna D. Prevalence of low birth weight and associated factor among neonate born at Jimma medical center (JMC), Jimma, South Western Ethiopia. Transl Biomed. 2019;10(1):156.

24. Zeleke BM, Zelalem M, Mohammed N. Incidence and correlates of low birth weight at a referral hospital in Northwest Ethiopia. Pan African Medical Journal. 2012;12(1). 
25. Wubetu AD, Amare YE, Haile AB, Degu MW. Newborn Birth Weight and Associated Factors Among Mother-Neonate Pairs in Public Hospitals, North Wollo, Ethiopia. Pediatric Health, Medicine and Therapeutics. 2021 Mar 9;12:111-8.

\section{Figures}

\section{Birth weight}

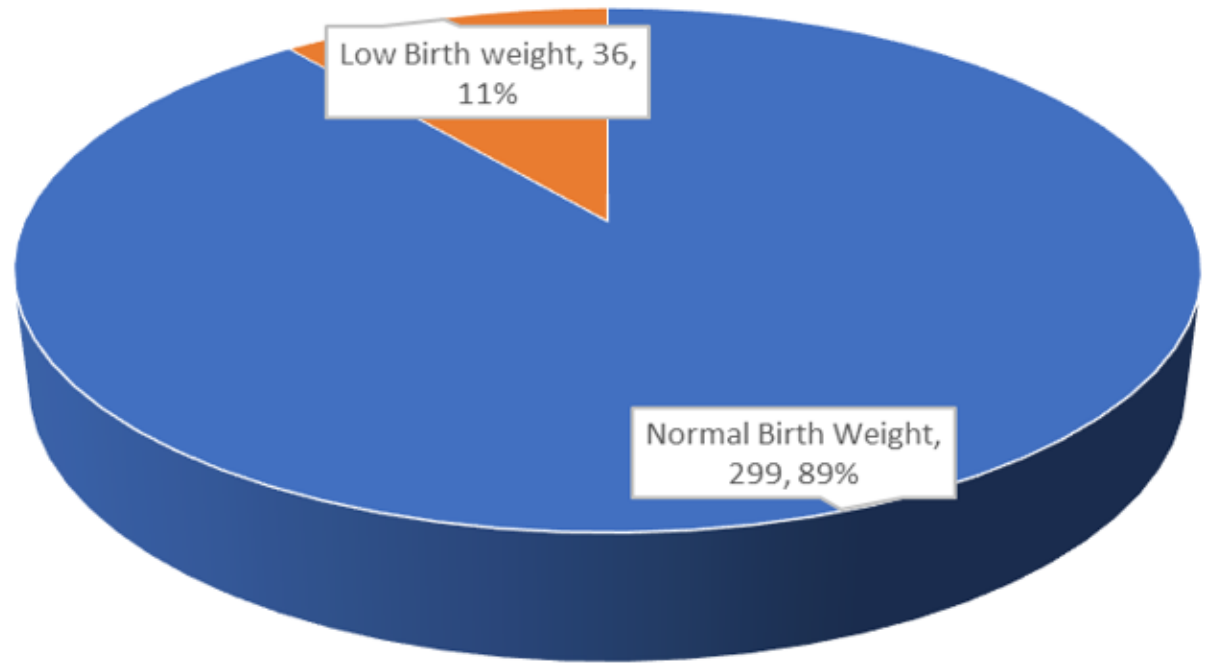

- Normal Birth Weight $\quad$ - Low Birth weight

\section{Figure 1}

Pie chart of low birth weight during the era of COVID 19 at Assosa General Hospital, Ethiopia, 2020 